\title{
The Effect of Self-regulated Strategy Instruction and Behavioral Consultation on Motivation: A Longitudinal Study on the Effect of School-Based Interventions in Secondary Education
}

\section{OPEN ACCESS}

Edited by:

Jesus de la Fuente, University of Almería, Spain

Reviewed by:

Stefanie Chye,

Nanyang Technological University, Singapore Angela Jocelyn Fawcett,

Swansea University, United Kingdom

*Correspondence:

Alexander Minnaert a.e.m.g.minnaert@rug.nl

these authors have first co-authorship.

Specialty section: This article was submitted to Educational Psychology, a section of the journal Frontiers in Education

Received: 21 April 2017 Accepted: 03 November 2017 Published: 24 November 2017

Citation:

Minnaert A, Prince $A$ and Opdenakker M-C (2017) The Effect of

Self-regulated Strategy Instruction and Behavioral Consultation on

Motivation: A Longitudinal Study

on the Effect of School-Based Interventions in Secondary Education.

Front. Educ. 2:61. doi: 10.3389/feduc.2017.00061

\author{
Alexander Minnaert ${ }^{1 * \dagger}$, Arnout Prince ${ }^{2 \dagger}$ and Marie-Christine Opdenakker ${ }^{3}$ \\ ${ }^{1}$ Department of Special Needs Education and Youth Care, University of Groningen, Groningen, Netherlands, ${ }^{2}$ Inholland \\ University of Applied Sciences, Hoofddorp, Netherlands, ${ }^{3}$ University of Groningen, Groningen, Netherlands
}

Studies show a decrease in students' motivation in secondary education. Hence, it was investigated whether training of teachers could stop this decline. Two interventions were implemented in prevocational secondary education, being self-regulated strategy instruction and behavioral consultation combined with strategy instruction. The longitudinal effects of the two interventions were tested on the goal orientations of 279 students. The growth curves show a long-term effect of the intervention combining teacher consultancy with strategy instruction on task orientation, ego-enhancing orientation, and ego-defeating orientation as compared to the control condition. For the strategy instruction only condition, only effects on ego orientation were found. The outcomes suggest that combining the instruction of self-regulation strategies with teacher consultation on student problemsolving can stop the downward trend in student motivation, even on the long term.

Keywords: self-regulation, motivation, goal-orientations, interventions, multilevel growth curve analysis, prevocational secondary education

\section{INTRODUCTION}

Motivation in secondary education is a topic of interest. Motivation to learn is considered indispensable for a successful academic career. Students' motivation determines what tasks they choose, how much effort they invest in a task, and how they interpret feedback given on their performance. On the long run, this influences students' perception of own academic ability and willingness to start and persist in academic tasks (Morgan and Fuchs, 2007). Studies have shown a decrease of student motivation from the start of secondary education (e.g., Gottfried et al., 2001; van der Veen and Peetsma, 2009; Opdenakker et al., 2012). This can have detrimental consequences for students' performance and ultimately the tendency to stay in school (Alexander et al., 1997). Among students of lower educational tracks, such as prevocational secondary education, drop-out levels are above average (see Lamb et al., 2011). This group of students has a higher risk of being diagnosed with learning difficulties and being confronted with academic failure. Repeated negative perceptions of academic performance can lead to a downward spiral of decreasing motivation, especially when the students do not have the ability to regulate their own motivation and learning behavior (Dickhäuser et al., 2011).

Additionally to the consequences for the students' academic careers, students' motivation also has consequences for the way the students can be taught. Teachers often consider student motivation to be of important influence on classroom and teacher behavior, as well as, in the long run, on academic 
performance (Addison and Brundrett, 2008). However, what can be done to foster student motivation often remains a difficult question for teachers to answer (Perry et al., 2006). Students can be motivated by giving them a sense of competence or by making the task interesting (Hidi and Harackiewicz, 2000). In order to remain motivated over time, the students should learn to regulate their own motivation and learning behavior (Lüftenegger et al., 2012). Teachers need skills and knowledge in order to interact effectively with students in order to teach them to self-regulate and to foster motivation, especially in the case of students with special educational needs. In order to stop the decrease of students' motivation, we tested the long-term effects of two interventions on student outcomes in terms of self-regulation and motivation in prevocational secondary education.

In the last years, about $50 \%$ of the adolescents in the Netherlands attended prevocational education. Among this percentage, there is considerable drop-out, while a high proportion of pupils are delayed in graduating. Moreover, the prevalence of problem behaviors in this group of adolescents is considerably higher compared to their peers attending high school. Knowing that students from low socioeconomic backgrounds are overrepresented in the lowest school type and that the percentage of early school leavers in the lowest school type is about three times higher than in higher school types (The State of Education in the Netherlands, 2014) a lot of students in the lowest school type are at risk. Great efforts are invested to keep these pupils on track. Unfortunately, these efforts are based predominantly on descriptive research that fails to provide a deeper understanding of major factors linked with school failure and drop-out.

Hence, teacher's professionalism is seen as a key factor in determining whether a pupil receives sufficiently individualized special educational support and education in a class or group (The State of Education in the Netherlands, 2014). It is crucial that teachers are given ample opportunity and take responsibility to professionalize their skills in this area. The ability to differentiate between individual needs and tailor the support to these needs is particularly important. This underscores the need for professionalization, especially in the context of prevocational education. The prevalence of learning and behavioral disorders requires adequate monitoring and effective intervention procedures to reduce study delay and early drop-out and to motivate these students.

\section{Motivation}

A predominant motivational theory is achievement goal theory, linking goals, ability, effort investment, and self-regulation. This theory states that students can have different goal orientations that influence their perception, choices, and behavior. Within this theory, a distinction is made between task orientation and ego orientation (Nicholls, 1984). Task orientation means that students want to demonstrate mastery of the task or learn new things. This is self-referenced, i.e., students want to perform according to their own abilities and learning is considered to be an end in itself. Ego orientation means that students want to show high capacity to peers. This is norm-referenced, i.e., students want to perform as well or better than others, and avoid showing low ability. Learning is at most considered a means. Other authors have made comparable distinctions. This would lead, however, too far beyond our scope; for a full overview of theoretical approaches to goal orientation, we refer the interested reader to Kaplan and Maehr (2007).

Goal orientations have consequences for students' interpretation of performance feedback and the effort invested (Minnaert, 2013). Task-orientated students consider performance feedback as feedback on the task and not so much on their level of ability. Additionally, they consider the effort they invest in the task and their performance on the task to co-vary. This leads them to choose tasks of moderate difficulty, since then they have a reasonable chance of succeeding. For ego-oriented students, the amount of effort invested in the task depends on their expectations of own ability. When low ability is assumed, the main motive becomes avoiding failure. This is done by choosing easy tasks and decreasing investment of effort. When high ability is assumed, either the chance for a successful outcome is maximized by choosing moderate task difficulty or highly difficult tasks are chosen, on which others fail, so succeeding would mean great success. These strategies followed by ego-oriented students were labeled, respectively, ego defeating and ego-enhancing orientation (Skaalvik, 1997).

In other words, perceived ability on a task is of importance to students when choosing tasks and deciding how much effort they will invest in task performance. Feedback from the environment is determining for the perceived ability. Successful task completion leads to an increase of perceptions of ability. Negative feedback, however, can lead to negative perceptions of own ability and, when experienced repeatedly, lead to downward spirals (Dickhäuser et al., 2011). Students with learning difficulties are in risk of having a history of repeated negative academic experiences. This can lead to decrease the perceived ability and anxiety as well as avoidance behavior.

Research has shown that, during adolescence, both the feelings of competence as well as the task interest and, therefore, perceived ability and task orientation of students decline. Ego orientation, however, inclines during adolescence (Wigfield et al., 2006). For long, it was assumed that task orientation was contributive to educational situations and ego orientation detrimental (Wolters et al., 1996). Therefore, research focused on aspects of the learning environment that would support task orientation and minimize ego orientation, for example, cooperative learning (Hanze and Berger, 2007), positive feedback (Rakoczy et al., 2013), and autonomy support (Reeve and Jang, 2006). Lately, research has shown that ego-enhancing goal orientation can positively contribute to positive academic outcomes (Wolters et al., 1996; Pintrich, 2000a; Dickhäuser et al., 2011).

\section{Self-regulation and Motivation}

As stated in the context of achievement goal theory, motivation and self-regulation are linked. Self-regulated learning means to be explicitly and purposefully planning, monitoring, and evaluating one's own learning processes (Zimmerman, 1990). Self-regulated students are goal-directed, construct their learning process, and monitor, control, and regulate their cognitive and metacognitive strategies, motivation, and behavior (Minnaert and Vermunt, 2010). It demands for forethought and planning, monitoring and controlling, and evaluation (Pintrich, 2000b; Zimmerman, 2000). 
When the students are able to regulate their learning, they are better able to focus on the task and their own performance and have a higher feeling of personal influence on the learning outcomes. Additionally, motivation is an important part of self-regulated learning. Goal orientations and efficacy beliefs are being used in order to plan and monitor learning behavior. Motivation is being controlled and monitored in order to maintain effective learning. Learning feedback is used in order to evaluate and adapt the learning process to environmental demands (Zimmerman, 1990, 2000; Pintrich, 2000b).

The use of self-regulation strategies has been shown to decrease over time (Ahmed et al., 2013). Students with learning difficulties often lack self-regulation skills (Graham and Harris, 2003). When they have low perceived ability, this influences the process of regulation as well as the motivation to learn. Furthermore, monitoring and controlling their own learning behavior is problematic for students with learning problems. In order to boost self-regulated learning, all three main components of self-regulation have to be influenced, being (meta)cognition, motivation, and behavior (Zimmerman, 1990). It has been shown that the effects of interventions focusing on self-regulation strategies only are difficult to maintain over time (Campione, 1987). Additionally, self-regulation and motivation are reciprocally related, influencing each other (Pintrich and De Groot, 1990; Minnaert, 1999; Pintrich, 2000a; Miller and Brickman, 2004), suggesting a combined approach within interventions to bridge theory, research, and practice (Hulleman and Barron, 2016).

\section{The Interventions}

In order to achieve a durable change in the motivation of vulnerable students, we implemented two promising interventions in this study, being Self-Regulated Strategy Development (SRSD) (Harris and Graham, 1996) and behavioral consultation (BC) (Bergan, 1977) with an integration of SRSD.

\section{Self-Regulated Strategy Development}

Self-regulated strategy development is a well-acclaimed approach to teaching writing strategies to students with learning difficulties. The main goal is teaching self-regulation. The students are being taught knowledge and skills on how to regulate their motivation and learning behavior. Examples of knowledge taught are strategic knowledge on self-regulation and problem-solving strategies, or content knowledge on what strategies can be used and how. Examples of skills taught are self-regulation skills such as planning, self-monitoring, and self-reinforcement, or study skills, such as rehearsal, structuring, and use of resources. Additionally, motivation is boosted by visualization of progress and emphasizing the importance of effort on task completion. This is expected to lead to improved self-regulation, improved study skills, improved performance, and ultimately improved self-efficacy.

This knowledge and these skills are being taught using a six stage teaching structure combining explicit teaching with teacher-student interaction and tailored instruction. The first stage is Develop background knowledge, in which the teacher activates student's knowledge relevant for the strategy. The second step is Discuss it, in which the teacher and the student discuss the strategy and adapt it to the students understanding and skills. The third step, Model it, involves the teacher modeling the strategy. The fifth step, Memorize it, consists of rote learning of the strategy and the self-instructions, and is especially important for students with memory or concentration problems. The fifth step, Support it, entails the student practicing the strategy while assisted by the teacher or peers. Eventually the sixth step, Independent performance, means that the student performs the strategy without assistance or monitoring. The last two steps mean that the teacher gradually fades out of the instruction. Not all phases have to be used in every occasion and phases can be repeated if necessary.

This approach aims at offering a specific approach to the individual student's problems as well as an internalization of selfregulation strategies. By using explicit teaching and structured feedback students with learning problems are served in their needs. This way of teaching has shown to be most effective for students with problems with memory, attention or information processing. Especially among students with learning difficulties, the SRSD-approach has been shown to deliver good improvements in writing skills and-at a more generic level—on self-regulating behavior, with effect sizes ranging from 1.1 till 2 (Graham and Harris, 2003). Additionally, immediate positive feedback on their task performance as well as gain in ability to overcome academic problems is expected to boost the students' perceived ability and to increase their interest in academic tasks. Additionally, by using interactive teaching, tailor-made solutions and fading-out, the students are triggered and supported to gain ownership in knowledge and self-regulatory skills. This constructivist learning contributes to task orientation (Nie and Lau, 2010).

The role of goals in self-regulated learning is already widely emphasized for a long time [see, e.g., Zimmerman (1999)]. Besides, goal orientations are depending on self-regulatory skills in initiating goal-directed behaviors and bringing them to a successful end (Gollwitzer and Sheeran, 2006). By and large, more attention should be drawn on the impact of self-regulation on the development of goal orientations over time. This might shed light on why students are engaged to do what they do and why they are not committed to do what is self-chosen or expected of them (Minnaert, 2013). Hence, SRSD with an explicit focus on generic self-regulatory skills is, therefore, assumed to have impact of students goal orientations, i.e., enhancing an approach to enjoy new and challenging tasks, i.e., task orientation, and diminishing an approach to outperform classmates, i.e., ego-orientation (Anderman et al., 2002).

\section{Behavioral Consultation}

Behavioral consultation is a problem-solving approach that has its roots in student counseling in order to improve the performance and behavior of students with special educational needs (Bergan, 1977; Shapiro, 1987; Gutkin and Curtis, 1999). The consultant helps the consultee identifying and analyzing the problem with a client, and devising, implementing an evaluating a plan to solve the problem. In the case of implementation in education, the consultee can be a teacher and the client a student with learning and/or behavioral difficulties. The problem is approached from a behavioral perspective and with a holistic view on the person and the environment. The solution can entail changes 
in the environment as well as in the person. The model consists of four stages, i.e., Problem identification, Problem analysis, Plan implementation, Problem evaluation. In the first two stages, the consultant and consultee collaborate to identify the problem and gather relevant information about the client and the environment. The consultant asks questions and consults with knowledge or experience. The consultee provides information and decides what the plan will be. In the third and fourth stage, the plan is implemented and monitored by the consultee and evaluated after which is decided what the next step will be.

Behavioral consultation has been shown to effectively improve student performance, to reduce disruptive behavior, and to improve attendance (Shapiro and Kratochwill, 2000) and on-task behavior (Dunson et al., 1994). Especially when a step-by-step plan is used systematically, adherence is shown to the treatment plan, and the evaluation is done by comparing with baseline behavior, the effects on student behavior change are significant (MacLeod et al., 2001). Additionally to having beneficial effects for students, $\mathrm{BC}$ has been shown to be effective to contribute to teacher professionalization. Consultation has been shown to increase innovative and experimental teaching (Alinder, 1994), to increase teacher skills and satisfaction (Kaiser et al., 2009), to improve the teachers' ability to meet the needs of special needs students (Seppälä and Leskelä-Ranta, 2006), to decrease teacher stress (Tunnecliffe et al., 1986), and to facilitate the development of a learning organization that is able to cope with the challenges of inclusive education (Nevin et al., 1990). Additionally, shared vision and increased teacher communication, which are organizational level outcomes of consultation, have been shown to significantly influence both student achievement (Lomos et al., 2011), and student motivation (Opdenakker and Van Damme, 2007). However, to effectively change teacher behavior, school wide implementation, support from the school administrator, and on-the-job training are needed (van den Berg et al., 1999).

\section{Integration of BC and SRSD}

With the SRSD intervention, students experiencing learning difficulties are taught strategies. Using these strategies, the students can gain control over their performance on academic tasks, boost their perceptions of ability, and direct their effort toward the task. The change brought forth by SRSD remains, however, local. It remains limited to the individual student to whom the specific strategies are taught, and to the teacher teaching the strategies to the student. The integrated version of BC and SRSD was constructed to strive toward change that is durable, school wide, and on the multiple aspects of motivation. This intervention adopted the holistic approach to students' learning problems of BC and integrated the specific approach to students' learning problems of SRSD in it. Literature has shown that, in order to achieve an effect on learning behavior, both specific and general knowledge and skills have to be included in the intervention (Campione, 1987; Miller and Brickman, 2004). In this format, the learning behavior of the individual student is analyzed taking the whole learning environment in regard. By changing the learning environment and teaching tailor-made self-regulation strategies, the learning behavior is boosted. This effect is expected to transfer to other students and other subject domains, since the intervention strives toward an optimization of the learning environment and is implemented school-wide. Additionally, this approach has its effects on the teachers. The teachers are constantly stimulated to professionalize. Not only do they have to reflect on the effectiveness of their interaction with the student but also they consult each other and communicate in order to achieve a school-wide vision on solving students learning problems. The parts of BC and SRSD that were expected to influence student cognition, motivation, and behavior were integrated. Based on a review of the literature on effective interventions, a combination of an in-depth behavioral and a holistic approach, as well as the combination of intervening on teacher level as well as on organizational level, is discerned to lead to a durable change in student motivation and self-regulation (Prince, 2014).

\section{The Present Study}

The aim of the study was to evaluate the effect of these interventions on the development of motivation of the students of prevocational education, since these students are most at risk for academic failure and a downward spiral of motivation. By effectively solving students' problems with learning and improving students' learning behavior, we expected that students' perceived ability would be boosted, and that they would be provided with positive learning experiences, leading to enjoyment of the learning task. We compared the development of motivation over a time span of 18 months of students with whom the interventions were implemented to the development of motivation of a group of students without a treatment. Based on the literature, we expected that we would observe a decline over time in task orientation and incline over time for both ego-enhancing and ego-defeating orientation would for students in the control condition (Anderman et al., 2002). For student in the intervention conditions, however, were expected a positive effect on the motivation, based on the explicit connection of learning, self-regulation, and motivation. Therefore, we expected to observe that the decline in motivation amongst the students receiving one of the interventions would be less steep then the decline of the students not receiving either of the interventions. Over time, this effect would be most noticeable for the students for whom BC was combined with SRSD. For the SRSD intervention, we expected a short-term positive effect on task orientation, as well as less incline in ego orientation. For the BC and SRSD combination condition, we expected effects on short term on all variables, although most of the effects were expected on the long term.

\section{MATERIALS AND METHODS}

\section{Participants}

Participants were 279 first grade students of four secondary schools in four distinct medium sized towns in the northern part of the Netherlands. They all attended prevocational secondary education. The sample is comprised of $47 \%$ boys.

\section{Procedure}

In this study, we used a pretest posttest follow-up experimental control group design with two treatment groups, each consisting 
of students of a separate school, and a control group, consisting of students of two other schools. It was opted to include the students of two schools in order to increase representativeness of the control group. We measured the student outcomes at three time points: a before-implementation pretest, an after-implementation posttest, and a 1 year later, follow-up test. Not all the participant completed all tests, but they completed at least two tests. Further analysis revealed that missing was completely at random. The number of participants per condition per measurement as well as the total number of unique participants are represented in Table 1. Active consents were derived from the participating schools, teachers, and parents in line with the ethical regulations of the Netherlands Organization for Scientific Research (NWO) and the Ministry of Education.

The interventions were implemented between pretest and posttest. For both interventions, we used three times a $2 \mathrm{~h}$ training session and a follow-up session. The teachers in the SRSD intervention training sessions were the Dutch and English language teachers of the students participating in the study. The teachers in the combined intervention training sessions were all teachers of the students participating in the study as well as the school administrators, since the BC intervention demanded school-wide implementation. In both interventions, we adapted the intervention contents based on SRSD in such a fashion that the domain specific writing strategies of the intervention were encapsulated by more general self-regulated learning strategies. The $\mathrm{BC}$ in the combined condition was aimed at optimizing student remedial care. The first co-author led the training sessions in both conditions and was assisted by a colleague. The school administrators had communicated that participation of training sessions was mandatory. To provide a good fit with the educational context, we made the participating teachers responsible for judging when the training contents could be properly implemented in the classroom. We assessed the implementation fidelity during the follow-up coaching session in the form of teacher appraisals of the interventions applicability and change of teacher vision in line with the interventions. A schematic representation of the research design can be found in Table 2.

TABLE 1 | Number of participants per measurement moment.

\begin{tabular}{lcccc}
\hline & Pretest & Posttest & Follow-up & Unique participants $^{\mathbf{a}}$ \\
\hline SRSD & 72 & 56 & 42 & 75 \\
BC and SRSD & 73 & 33 & 53 & 60 \\
Control & 139 & 139 & 126 & 144
\end{tabular}

aParticipants who completed the test in at least two measurement moments.

$S R S D$, self-regulated strategy development; $B C$, behavioral consultation.

\section{SRSD Training and Coaching Sessions}

The first training session dealt with theory of self-regulation and analysis of student self-regulating behavior. The second training session dealt with devising a plan and teaching a self-regulation strategy to a student. The teachers were handed a strategy teaching planning scheme consistent with the phases of SRSD. During the third training session, the whole model was trained by making use of three deliberately chosen and target group representative case studies. During the follow-up session, the teachers had the opportunity to ask questions. This created the possibility to, when needed, re-activate the intervention. For a complete overview of the SRSD training and coaching sessions, the reader is referred to Table A1 in Appendix.

\section{BC and SRSD Combined Training and Coaching Sessions}

The first training session dealt with problem identification and problem analysis. The teachers were handed an analysis scheme consistent with the stages of $\mathrm{BC}$ and received training in consultation. The second training session dealt with devising a plan and teaching a self-regulation strategy to a student. The teachers were handed a strategy teaching planning scheme consistent with the phases of SRSD. The third training session dealt with in-class implementation and evaluation. The follow-up session was held with only the school administrator and dealt with independent implementation of the BC and SRSD combined approach in order to work toward ownership by the school. For a complete overview of the BC and SRSD combined training and coaching sessions, the reader is referred to Table A2 in Appendix.

\section{Instruments}

All instruments we used were self-report questionnaires, and were answered either electronically or paper-pencil, depending on the schools' facilities. The items could be scored on a 5-point Likert scale ranging from "totally disagree" to "totally agree." Prototypical example items and scale reliabilities are to found in Table A3 in Appendix.

We used the Goal Orientation Questionnaire (Seegers et al., 2002) to measure the students' motivation. The Task orientation subscale consisted of five items concerning the extent to which the students enjoyed new and challenging tasks. The Ego-enhancing orientation subscale consisted of six items concerning the extent to which the students enjoy outperforming their classmates. The Ego-defeating orientation subscales consisted of six items, concerning the extent to which the students are afraid to show failure. In this study, the reliability across the three measurement moments were $\alpha=0.83$ for the Task orientation subscale, $\alpha=0.85$ for the Ego-enhancing orientation subscale, and $\alpha=0.87$ for the Ego-defeating orientation subscale.

TABLE 2 | Design of the study.

\begin{tabular}{|c|c|c|c|c|c|c|c|}
\hline Time & & Start & & 1 month & & 3 months & 15 months \\
\hline
\end{tabular}

antervention conditions. 


\section{Analysis}

For the analysis of the data, we used multilevel longitudinal (growth) analysis. We entered three levels into the model in order to do justice to the multilevel structure of the data. Level one is the measurement level, level two is the student level, and level three is the class level. An advantage of multilevel analysis is that it is capable of handling missing data. We included gender in the model to control on possible gender effects. It was entered as a dummy variable, with boys receiving the score " 0 " and girls receiving the score " 1 ." We entered the condition variable with dummy variable for the experimental conditions, so that the control conditions functioned as the comparison. For each variable, we tested models with linear and quadratic effects against models with only linear time effects, and models with gender against models without gender. To test the models against each other, we used likelihood ratio tests (Snijders and Bosker, 2012).

After establishing what was the best growth model for the data, the parameters of the models were tested using Wald's $t$-test. Next to using an alpha of 0.05 for significance testing, we used an alpha of 0.10 to identify trends in the data, since the power to detect relevant effects was hindered by the rather small sample sizes of the experimental conditions (Cohen, 1988), and educational interventions are known to have on average small to medium effect sizes (0.40; Hattie, 2012). The test was performed two-sided, since no clearly defined hypotheses could be formulated and the analysis of the effects would be merely explorative.

\section{RESULTS}

\section{Treatment Fidelity}

In the case of the SRSD-only condition, the teachers indicated during the follow-up coaching session that they had implemented the intervention in the classroom. The teachers judged the interventions as useful and suitable for classroom application. The teachers could offer multiple examples of how they had implemented the intervention and how it had worked out.

In the case of the $\mathrm{BC}$ and SRSD combined condition, the school administrator indicated during the follow-up coaching session that the approach was found to be especially useful when used for group-wise evaluating the students and solving student problems during groupwise evaluations by the teachers of student performance. This was indeed in line with the core ideas behind the approach. Moreover, they indicated that the school was working to further develop the approach to make it even more suitable to their demands, indicating that the school had developed ownership of the approach.

\section{Descriptives}

The means of the variables, their SDs at the different time points, and effect sizes can be found in Table 3. Noteworthy are the medium downward effect sizes for task orientation for both the control and SRSD condition. The BC and SRSD combined condition holds a flat development over time. For ego-enhancing orientation, the same trend is discernable, although the effect size is weak instead of medium.

\section{Multilevel Growth Curve Models}

The results of the multilevel growth curve analysis are displayed in Table 4 per goal orientation.

\section{Task Orientation}

The linear model was found to be the best fitting model for the data. We found no significant differences in the deviance tests for models including quadratic parameters and, therefore, decided that the simplest model would be the best to use.

We found no differences in intercepts between the conditions. We did find a significant decline in task orientation for the control condition $(p<0.05)$. For the SRSD condition, the development of task orientation did not differ significantly from the control condition. However, we found that the difference between the decline in task orientation of the SRSD and BC condition and the decline in task orientation of the control condition over time approached significance $(p<0.10)$. This suggests a trend that, in the long run, the task orientation of the students in the SRSD and $\mathrm{BC}$ condition shows less decline than the students in the control condition and the SRSD condition. The development of task orientation is represented in Figure 1.

We found a significant difference in deviance scores $(p<0.05)$ for a model including a fixed effect for gender as well as fixed

TABLE 3 | Descriptives of the variables by condition and effect sizes.

\begin{tabular}{|c|c|c|c|c|c|}
\hline Orientation & Condition & $\begin{array}{l}\text { Pretest } \\
\text { M (SD) }\end{array}$ & $\begin{array}{l}\text { Posttest } \\
\text { M (SD) }\end{array}$ & $\begin{array}{c}\text { Follow-up } \\
\text { M (SD) }\end{array}$ & ES \\
\hline Task orientation & $\begin{array}{l}\text { Self-Regulated Strategy Development (SRSD) } \\
\text { Behavioral consultation (BC) and SRSD } \\
\text { Control }\end{array}$ & $\begin{array}{l}3.92(0.69) \\
3.76(0.76) \\
3.82(0.66)\end{array}$ & $\begin{array}{l}3.88(0.74) \\
3.77(0.74) \\
3.65(0.78)\end{array}$ & $\begin{array}{l}3.50(0.71) \\
3.62(0.57) \\
3.44(0.83)\end{array}$ & $\begin{array}{l}-0.06 /-0.61 \\
+0.01 /-0.18 \\
-0.26 /-0.58\end{array}$ \\
\hline Ego enhancing & $\begin{array}{l}\text { SRSD } \\
\text { BC and SRSD } \\
\text { Control }\end{array}$ & $\begin{array}{l}3.02(0.98) \\
2.96(0.96) \\
3.06(0.91)\end{array}$ & $\begin{array}{l}3.11(0.80) \\
2.97(1.09) \\
2.91(0.82)\end{array}$ & $\begin{array}{l}2.72(0.80) \\
3.07(0.82) \\
2.81(0.89)\end{array}$ & $\begin{array}{l}+0.09 /-0.31 \\
+0.01 /+0.11 \\
-0.16 /-0.27\end{array}$ \\
\hline
\end{tabular}

ES, effect sizes represented for posttest versus pretest and follow-up versus pretest, respectively. 
TABLE 4 | Multilevel growth curve models.

\begin{tabular}{|c|c|c|c|c|c|c|}
\hline & \multicolumn{2}{|c|}{ Task orientation } & \multicolumn{2}{|c|}{ Ego-enhancing } & \multicolumn{2}{|c|}{ Ego-defeating } \\
\hline & Coefficient & SE & Coefficient & SE & Coefficient & SE \\
\hline \multicolumn{7}{|l|}{ Fixed effects } \\
\hline Intercept & $3.952^{\star \star}$ & 0.100 & $3.268^{\star \star}$ & 0.112 & $2.066^{\star \star}$ & 0.121 \\
\hline Time & $-0.023^{\star \star}$ & 0.005 & $-0.046^{\star \star}$ & 0.023 & 0.0372 & 0.025 \\
\hline Time $^{2}$ & & & 0.002 & 0.001 & $-0.003^{\star \star}$ & 0.002 \\
\hline SRSD & -0.035 & 0.179 & -0.064 & 0.183 & -0.180 & 0.121 \\
\hline SRSD and BC & -0.211 & 0.163 & -0.106 & 0.167 & -0.163 & 0.115 \\
\hline SRSD $\times$ time & -0.007 & 0.010 & 0.072 & 0.045 & $0.085^{\star}$ & 0.049 \\
\hline SRSD $\times$ time $^{2}$ & & & $-0.005^{\star}$ & 0.003 & $-0.006^{\star \star}$ & 0.003 \\
\hline $\begin{array}{l}\text { SRSD and BC } \times \text { time } \\
\text { SRSD and } B C \times \text { time }^{2}\end{array}$ & $0.015^{\star}$ & 0.009 & $0.022^{\star \star}$ & 0.010 & $0.023^{\star \star}$ & 0.009 \\
\hline Gender & $-0.297^{\star \star}$ & 0.099 & $-0.399^{\star \star}$ & 0.086 & & \\
\hline Gender $\times$ SRSD & $0.337^{\star \star}$ & 0.170 & & & & \\
\hline Gender $\times$ SRSD and BC & 0.266 & 0.172 & & & & \\
\hline \multicolumn{7}{|l|}{ Random effects } \\
\hline \multicolumn{7}{|l|}{ Level 3 variance } \\
\hline Intercept & 0.035 & 0.021 & 0.048 & 0.029 & 0.000 & 0.000 \\
\hline Time & 0.000 & 0.000 & 0.000 & 0.000 & 0.000 & 0.000 \\
\hline Intercept $\times$ time & -0.001 & 0.001 & -0.000 & 0.001 & 0.000 & 0.000 \\
\hline \multicolumn{7}{|l|}{ Level 2 variance } \\
\hline Intercept & 0.233 & 0.038 & 0.482 & 0.059 & 0.401 & 0.055 \\
\hline Time & 0.000 & 0.000 & 0.001 & 0.000 & 0.001 & 0.000 \\
\hline Intercept $\times$ time & -0.000 & 0.003 & -0.010 & 0.004 & -0.005 & 0.004 \\
\hline \multicolumn{7}{|l|}{ Level 1 variance } \\
\hline Residual & 0.246 & 0.024 & 0.254 & 0.025 & 0.305 & 0.029 \\
\hline Deviance & \multicolumn{2}{|c|}{$1,462.899$} & \multicolumn{2}{|c|}{$1,652.361$} & \multicolumn{2}{|c|}{$1,666.147$} \\
\hline
\end{tabular}

${ }^{*} p<0.10 ;{ }^{* *} p<0.05$.

$S R S D$, self-regulated strategy development; $B C$, behavioral consultation.

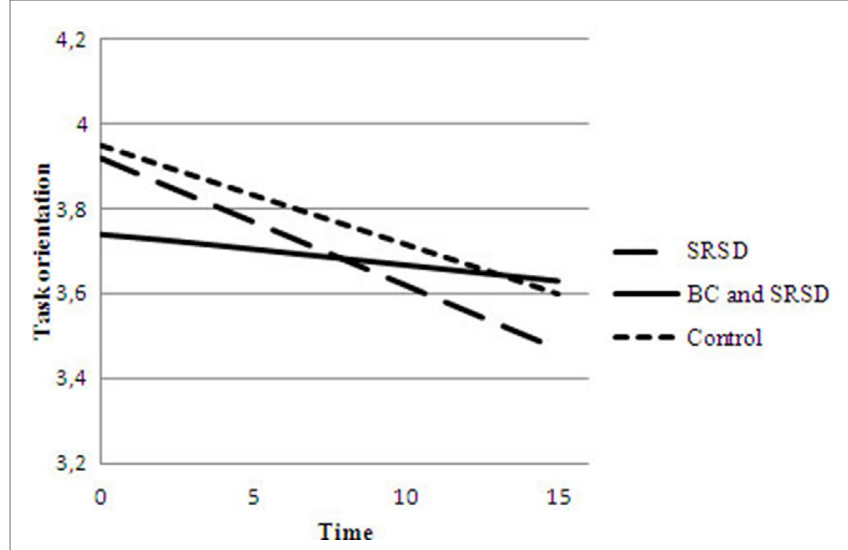

FIGURE 1 | Graph of the growth curves of task orientation. Time is displayed in months since the start of the intervention. Gender differences were not included in this representation.

effects for interaction of condition with effect as compared to a model without including gender as a predictor. Girls scored lower than boys in the control condition $(p<0.01)$. We did not find any differences in task orientation between the control condition and the SRSD and BC condition with regard to gender. We did find a significant interaction between the SRSD condition and gender $(p<0.05)$. This effect undid the difference between boys and girls observed in the control condition. In other words, we did not find gender differences for the students' motivation in the SRSD condition. No interaction effect of gender and task orientation score over time was found for any of the conditions. Gender did not have an effect on the way the interventions influenced the students' task orientation.

\section{Ego-Enhancing Orientation}

The model combining linear and quadratic effects was found to be the best fitting model for the data. We found no significant differences in the deviance tests between the linear and quadratic models. However, some quadratic parameters were found to be significant and, therefore, it was decided that the combination model showed the best fit for the data.

We found no differences in intercepts between the conditions. Additionally, we found a significant linear decline of ego-enhancing orientation for the control condition $(p<0.05)$. We found no difference in the linear effect of ego-enhancing orientation of the SRSD condition from the control condition. The quadratic effect of ego-enhancing orientation showed a trend of accelerated decline compared to the control condition $(p<0.10)$. With the ego-enhancing orientation of the SRSD and BC condition we observed a linear development, of which, the decline over time was significantly less than the decline observed for the control condition $(p<0.05)$. Apparently, ego-enhancing orientation of the students in de SRSD and BC condition shows less decline 
than the students in the control condition and the SRSD condition over time. The development of ego-enhancing orientation is represented in Figure 2.

We found a significant difference in deviance scores $(p<0.0001)$ for a model including a fixed effect for gender as compared to a model without including gender as a predictor. The girls scored lower than the boys all the conditions $(p<0.0001)$. No interaction effect of gender and ego-enhancing orientation score over time was found for any of the conditions. Comparable with task orientation, gender did not have an effect on the way the interventions influenced the students' ego orientation.

\section{Ego-Defeating Orientation}

The model combining linear and quadratic effects was found to be the best fitting model for the data. We found no significant differences in the deviance tests between the linear and quadratic models. However, some quadratic parameters were found to be significant and, therefore, it was decided that the combination model showed the best fit for the data.

We found no differences in intercepts between the conditions. No significant incline or decline in linear development of egodefeating orientation was found for the control condition. The quadratic effect was significant $(p<0.05)$, suggesting a stable trend at first, turning into a decline at the long term. We found a comparable development of ego orientation for SRSD condition, with even more explicit developments in the trends; the linear development of ego-defeating orientation showed a trend toward incline compared to the control condition $(p<0.10)$, and the quadratic slope showed significantly higher decline $(p<0.05)$. Comparable to the development of ego-enhancing orientation, we found that the ego-defeating orientation of the SRSD and BC condition showed a linear development, and that this development showed an incline over time, which differed significantly from the development of the control condition $(p<0.05)$. Over time, the students in the SRSD and BC condition scored higher

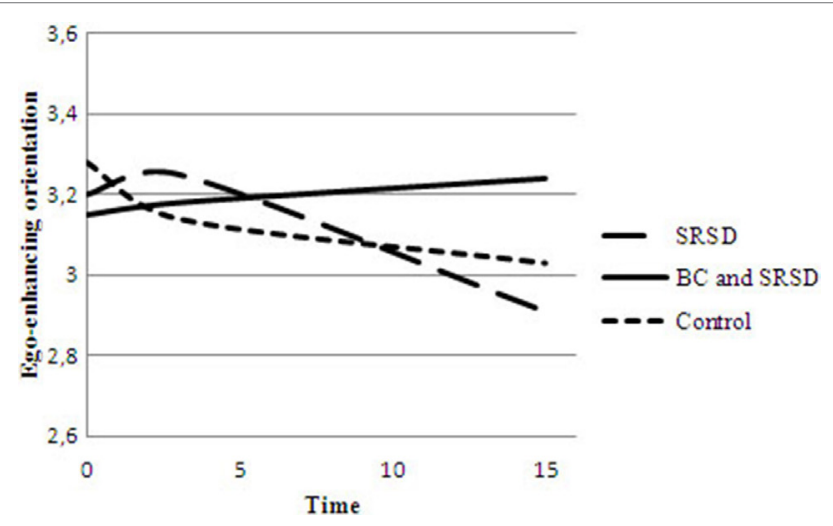

FIGURE 2 | Graph of the growth curves of ego-enhancing orientation. Time is displayed in months since the start of the intervention. Gender differences were not included in this representation. on ego-defeating orientation than the students in the other conditions. No effect of gender was found. The development of ego-defeating orientation is represented in Figure 3.

\section{DISCUSSION}

The BC and SRSD combined intervention appears to have an effect on the motivation of students: students showed less decline in motivation over time, even on the long term. Effects of educational interventions noticeable after more than 1 year are hard to achieve. Keeping this in mind, we want to point out that with the linear development of the goal orientation scores of the BC and SRSD combined condition as opposed to the quadratic development of the scores of the other conditions, the magnitude of these effects becomes dramatic on the long term. The addition of $\mathrm{BC}$ seems to be the determining factor for long-term effect in this case, since the SRSD only condition shows a strong drop in the motivation scores on the long term. Besides, other intervention research in the Netherlands converged with the long-term impact of BC in this respect, notwithstanding in primary education (Meijer et al., 2016). The construction of a coherent vision and a system that helps a school to work independently on the quality of teaching seems to act as powerful ingredients for a long-term effect on student motivation. Vision and a stimulating environment were shown to be productive for the teacher professionalization (Geijsel et al., 2009). Shapiro and Kratochwill (2000) emphasized the effectiveness of BC used to improve student performance, to reduce disruptive behavior, and to improve attending behavior. The added value and the effectiveness of $\mathrm{BC}$ is widely recognized in early childhood and primary education, especially in the context of needs-based, inclusive education. This method is, however, rather unfamiliar in secondary (vocational) education (Seppälä and Leskelä-Ranta, 2006). Effects of BC in other studies are convincing with large effect sizes on group level varying from 0.80 till 1.36 and across single-subjects from 0.97 at home and 1.06 at school with respect to teacher and parental satisfaction, communication, and perceptions of relationships with one another in primary education (see Sheridan et al.,

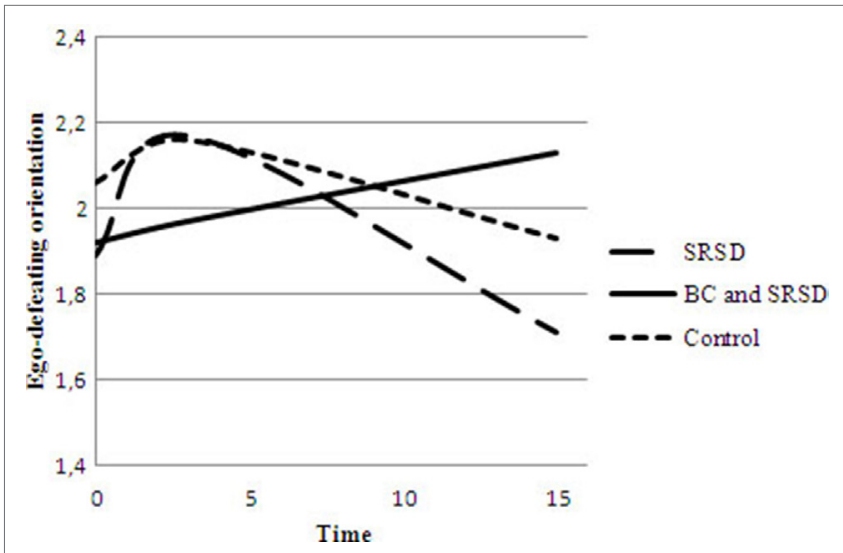

FIGURE 3 | Graph of the growth curves of ego-defeating orientation. Time is displayed in months since the start of the intervention. 
2006), but do not include fine-grained motivational outcomes on students level, and effect sizes on students in secondary education are absent. This is still an omission in literature on BC.

The SRSD only condition, on the other hand, did not lead to an effect on task motivation. Strong effects on self-regulatory writing skills and outcomes, as presumed from the aforementioned SRSD research, apparently do not show transfer effects on motivation outcomes. Only on ego-defeating orientation, a significant decline was observed on the long term. Ego orientation, however, has been shown to be detrimental to academic performance when it is not combined with task orientation (Pintrich, 2000a). The fact that the students in this condition show a drop in all motivation variable on the long term, rather suggests a trend toward a-motivation. One explanation for this developmental pattern could be that the students were made more conscious of their self-regulatory skills and performance due to the intervention, which lead to some effects on ego involvement in the short run, but to detrimental effects on the long run. The same explanation can be given from a teachers' perspective. The teachers can be made more conscious of the students' self-regulation, focusing more on the students than on the task. This is in line with the conclusion of Campione (1987), of Boekaerts and Minnaert (2003), and of MacLeod et al. (2001), that maintaining effects on metacognitive self-regulation is hard to achieve. Apparently, the strategy instruction has not (yet) led to the students durably perceiving themselves as self-regulated learners. In contrast to the large effect sizes reported by Graham and Harris (2003), we are obliged to question the generic approach of SRSD with respect to the motivational outcomes. It must be stated, however, that the outcomes in the meta-analysis of Graham and Harris (2003) were not motivationally in nature, but writing-related behavioral outcomes (i.e., story writing and word processing). Research integrating both perspectives is requested to disentangle the more durable cognitive, motivational, and behavioral effects.

This study has shown that only teaching self-regulation strategies are not sufficient to achieve a durable change in students' motivation. Moreover, for the students of prevocational education, with often history of academic failure and a high incidence of specific learning disorders and challenging behavior, the risk of a-motivation appears to be very existent, even when being taught self-regulation strategies. In order to achieve both a stop in the declining trend of motivation and make this effect durable, changes should be made not only in the teacher-student interaction and teaching of strategies but also in the learning environment in a more broad scope (Wang and Eccles, 2013). The school organization should collaboratively change their vision on problem-solving and offering more tailor-made teaching methods and curricula. By actively communicating and consulting each-other, the teachers can create a learning environment to offer room for both explicit and constructive teaching, but also enables the teacher to professionalize constantly (Lam et al., 2010). This school environment can be a match for challenges in the area of student motivation and self-regulation, especially in area of special educational needs (Smith and Bell, 2015). This is urgently required to realize inclusive and equitable quality education and lifelong learning (Education 2030, 2015).

\section{Limitations and Future Research}

Some limitations can be noted in the research design. A random assignment of schools to conditions was not performed, hence the requirements of an experimental design were not fully met. Since participation by schools could not be top down regulated in the Netherlands, a convenience sampling design was used. This raises the chance of school variables being accountable for the found effect instead of the intervention (Shadish et al., 2002). However, research in naturalistic settings cannot completely rule out facilitating factors in the, in this case, participating schools (Torgerson and Torgerson, 2007). Moreover, since especially in the SRSD and BC combination condition, a school wide involvement was demanded, here the presence of possible facilitating factors within a school will not so much have led to a false effect, but rather to faster implementation (Brophy, 1977). Therefore it may limit the generalizability of the findings on speed or quality of implementation, but an effect on motivation can still be noticed. Another limitation was the limited number of school per condition and limited number of participants per condition. Although the numbers were sufficient to do statistical testing, the small effect sizes demanded for larger samples. This was anticipated to some extend by identifying trends with an alpha of 0.10 . However, for future research, more schools and participants per condition and random assignment would be preferable to strengthen empirical evidence of the effects of these interventions. Additionally, keeping the complexity of the educational environment in mind, further research on the influence of specific contexts would contribute to successful implementation and perceived ownership (Boekaerts and Minnaert, 2003).

In this study, gender effects were found on task orientation and ego-enhancing orientation. In all these cases, girl scored lower than boys. Gjesme (1973) has stated that girls tend to systematically underestimate their subjective probability of success. In other words, girls are harsher on themselves then boys when it comes to expectancies of success. In this study, we did not observe any influence of gender on the effects of the interventions. However, neither did the interventions remediate the observed differences between boys and girls on motivation. It would be useful if the effects of gender on different aspects of motivation, as well as the consequences of these effects over time were further explored in research.

Longitudinal studies of motivation in secondary school are growing but still relatively scarce (Wigfield et al., 2006), making it hard to formulate precise hypotheses about the developmental patterns of student motivation over time. This additionally still leads to questions about especially the drop in motivation observed on the long term. Additional longitudinal studies are needed to gather knowledge on the trajectories of both student motivation and self-regulation over a long time. Likewise, more longitudinal studies on interventions aiming at the improvement of student motivation are needed in order to give more robust advice to teachers on what to do to "stop the drop" in motivation on the long term.

This study has shown that, even among students with a higher risk of learning disorders and behavioral challenges, measures can be taken that affect their motivation over a long time. Training of 
teachers to teach strategies, to consult each other, to stimulate constructive vision on students with special educational needs, and to professionalize themselves has shown to be productive for student motivation and self-regulation.

\section{CONCLUSION}

In the control group, we observed the expected decline over time for task orientation. We observed a decline in ego-enhancing orientation. For ego-defeating orientation, we observed a stable trend on the short term, and a decline on the long term. The observed decline in ego orientation for the control group was, however, not in line with our expectations.

The SRSD group showed similar developmental patterns with reference to the control group. Only for development of egodefeating orientation, we observed a stronger decline on the long term than in the control group. On the short term, we observed a trend toward an incline in ego-defeating orientation for the SRSD group. The development of ego-enhancing orientation of the students in the SRSD group was comparable to the development of the control group on the short term, but showed even a stronger decline after all. We found neither an effect, nor a trend of the intervention on task orientation.

The BC and SRSD combined group showed, however, different developmental patterns. On all of the goal orientation variables, we observed a linear development over time. This development showed less decline than the control group, or in the case of egodefeating orientation even an incline. These differences in developments were found to be significant for the ego-orientations and approaching significance for task orientation.

The results revealed some differences between boys and girls. No further interaction effects of gender and time or gender and intervention were found.

\section{REFERENCES}

Addison, R., and Brundrett, M. (2008). Motivation and demotivation of teachers in primary schools: the challenge of change. Education 3-13 36, 79-94. doi:10.1080/03004270701733254

Ahmed, W., van der Werf, G., Kuyper, H., and Minnaert, A. (2013). Emotions, self-regulated learning and achievement in mathematics: a growth curve analysis. J. Educ. Psychol. 105, 150-161. doi:10.1037/a0030160

Alexander, K. L., Entwisle, D. R., and Horsey, C. S. (1997). From first grade forward: early foundations of high school dropout. Sociol. Educ. 70, 87-107. doi: $10.2307 / 2673158$

Alinder, R. M. (1994). The relationship between efficacy and the instructional practices of special education teachers and consultants. Teach. Educ. Spec. Educ. 17, 86-95. doi:10.1177/088840649401700203

Anderman, E. M., Austin, C. C., and Johnson, D. M. (2002). “The development of goal orientations," in Development of Achievement Motivation, eds A. Wigfield and J. S. Eccles (San Diego, CA: Academic Press), 197-220.

Bergan, J. R. (1977). Behavioral Consultation. Columbus, OH: Merrill.

Boekaerts, M., and Minnaert, A. (2003). "Measuring behavioral change processes during an ongoing innovation program: scope and limits," in Powerful Learning Environments: Unravelling Basic Components and Dimensions, eds E. De Corte, L. Verschaffel, N. Entwistle, and J. van Merriënboer (New York: Pergamon), 71-87.

Brophy, J. E. (1977). Training teachers in experiments: considerations relating to nonlinearity and context effects. Paper Presented at the Annual Meeting of the
Concluding, in the BC and SRSD combined intervention condition, we observed a trend on task orientation which confirmed our expectations. Regarding both ego-enhancing and ego-defeating orientation, clear effects have been found in the BC and SRSD combined condition, but not in the expected direction. The SRSD intervention only shows an expected declining effect on ego-defeating orientation on the long term. The BC and SRSD combined intervention appeared to have an effect on the motivation of the students. Students did show less decline in motivation over time.

\section{ETHICS STATEMENT}

Active consent was retrieved from the school directors, teachers, and students participating in this study. Besides, the study was approved by the Netherlands Organization for Scientific Research (NWO) and the Ministry of Education.

\section{AUTHOR CONTRIBUTIONS}

This contribution stems from a successfully defended Ph.D. of AP at the University of Groningen in the Netherlands. This research was supported by grant 411-07-123 from the Netherlands Organization for Scientific Research assigned to AM. The research is not published in any kind of book or journal. It was in a different form part of a chapter in the Ph.D. AM and M-CO are both the supervisors of this Ph.D. and are the PI's of the grant and the Ph.D. project from onset till now.

\section{FUNDING}

This research was supported by grant 411-07-123 from the Netherlands Organization for Scientific Research (NWO) assigned to AM.

American Educational Research Association, New York, NY. Available at: http:// www.eric.ed.gov/contentdelivery/servlet/ERICServlet?accno=ED150201

Campione, J. C. (1987). "Metacognitive components of instructional research with problem learners," in Metacognition, Motivation, and Understanding, eds F. E. Weinert and R. H. Kluwe (Hillsdale, NJ: Lawrence Erlbaum), 117-140.

Cohen, J. (1988). Statistical Power Analysis for the Behavioral Sciences, 2nd Edn. Hillsdale, NJ: Lawrence Erlbaum.

Dickhäuser, C., Buch, S. R., and Dickhäuser, O. (2011). Achievement after failure: the role of achievement goals and negative self-related thoughts. Learn. Instr. 21, 152-162. doi:10.1016/j.learninstruc.2010.01.002

Dunson, R. M., Hughes, J. N., and Jackson, T. W. (1994). Effect of behavioral consultation on student and teacher behavior. J. Sch. Psychol. 32, 247-266. doi:10.1016/0022-4405(94)90017-5

Education 2030. (2015). Incheon Declaration and Framework for Action. Towards Inclusive and Equitable Quality Education and Lifelong Learning for All. Paris: UNESCO.

Geijsel, F. P., Sleegers, P. J. C., Stoel, R. D., and Krüger, M. L. (2009). The effect of teacher psychological and school organizational and leadership factors on teachers' professional learning in Dutch schools. Elem. Sch. J. 109, 406-427. doi:10.1086/593940

Gjesme, T. (1973). Achievement-related motives and school performance for girls. J. Pers. Soc. Psychol. 26, 131-136. doi:10.1037/h0034245

Gollwitzer, P. M., and Sheeran, P. (2006). Implementation intentions and goal achievement: a meta-analysis of effects and processes. Adv. Exp. Soc. Psychol. 38, 69-119. doi:10.1013/S0065-2601(06)38002-1 
Gottfried, A. E., Fleming, J. S., and Gottfried, A. W. (2001). Continuity of academic intrinsic motivation from childhood through late adolescence: a longitudinal study. J. Educ. Psychol. 93, 3-13. doi:10.1037//0022-0663.93.1.3

Graham, S., and Harris, K. R. (2003). "Students with learning disabilities and the process of writing: a meta-analysis of SRSD studies," in Handbook of Learning Disabilities, eds H. L. Swanson, K. R. Harris, and S. Graham (New York, London: The Guilford Press), 323-344.

Gross, J. J., and John, O. P. (2003). Individual differences in two emotion regulation processes: implications for affect, relationships, and well-Being. J. Pers. Soc. Psychol. 85, 348-362. doi:10.1037/0022-3514.85.2.348

Gutkin, T., and Curtis, M. (1999). "School-based consultation: theory and practice. The art and science of indirect service delivery," in The Handbook of School Psychology, 3rd Edn, eds C. Reynolds and T. Gutkin (New York, NY: Wiley), 598-637.

Hanze, M., and Berger, R. (2007). Cooperative learning, motivational effects, and student characteristics: an experimental study comparing cooperative learning and direct instruction in 12th grade physics classes. Learn. Instr. 17, 29-41. doi:10.1016/j.learninstruc.2006.11.004

Harris, K. R., and Graham, S. (1996). Making the Writing Process Work: Strategies for Composition and Self-regulation. Cambridge, MA: Brookline Books.

Hattie, J. (2012). Visible Learning for Teachers. New York: Routledge.

Hidi, S., and Harackiewicz, J. M. (2000). Motivating the academically unmotivated: a critical issue for the 21st century. Rev. Educ. Res. 70, 151-179. doi:10.3102/00346543070002151

Hulleman, C. S., and Barron, K. E. (2016). "Motivation interventions in education: bridging theory, research, and practice," in Handbook of Educational Psychology, 3rd Edn, eds L. Corno and E. M. Anderman (New York: Routledge), 160-171.

Kaiser, L., Rosenfield, S., and Gravois, T. (2009). Teachers' perception of satisfaction, skill development, and skill application after instructional consultation services. J. Learn. Disabil. 42, 444-457. doi:10.1177/0022219409339062

Kaplan, A., and Maehr, M. L. (2007). The contributions and prospects of goal orientation theory. Educ. Psychol. Rev. 19, 141-184. doi:10.1007/s10648-006-9012-5

Lam, S. F., Cheng, R. W. Y., and Choy, H. C. (2010). School support and teacher motivation to implement project-based learning. Learn. Instr. 20, 487-497. doi:10.1016/j.learninstruc.2009.07.003

Lamb, S., Markussen, E., Teese, R., Sandberg, N., and Polesel, J. (2011). School Dropout and Completion: International Comparative Studies in Theory and Policy. Dordrecht, Heidelberg, London, New York: Spinger.

Lomos, C., Hofman, R. H., and Bosker, R. J. (2011). Professional communities and student achievement - a meta-analysis. Sch. Effect. Sch. Improv. 22, 121-148. doi:10.1080/09243453.2010.550467

Lüftenegger, M., Schober, B., van de Schoot, R., Wagner, P., Finsterwald, M., and Spiel, C. (2012). Lifelong learning as a goal - do autonomy and self-regulation in school result in well prepared pupils? Learn. Instr. 22, 27-36. doi:10.1016/j. learninstruc.2011.06.001

MacLeod, I. R., Jones, K. M., Somers, C. L., and Havey, J. M. (2001). An evaluation of the effectiveness of school-based behavioral consultation. J. Educ. Psychol. Consult. 12, 203-216. doi:10.1207/S1532768XJEPC1203_02

Meijer, W., Felder, V., Minnaert, A., and Veenstra, A. (2016). Over leerlingen gesproken... De IB'er als drijvende kracht achter de cultuuromslag die 'passend onderwijs' heet [Talking about Students ... The Internal School Coach as a Driving Force Behind the Cultural Change That Is Called Inclusive/Adaptive Education]. Dordrecht, The Netherlands: Instondo.

Midgley, C., Maehr, M.L., Hruda, L. Z., Anderman, E., Anderman, L., Freeman, K. E., et al. (2000). Manual for the Patterns of Adaptive Learning Scales (PALS). Ann Arbor, MI: University of Michigan.

Miller, R. B., and Brickman, S. J. (2004). A model of future-oriented motivation and self-regulation. Educ. Psychol. Rev. 16, 9-33. doi:10.1023/B:EDPR. 0000012343.96370 .39

Minnaert, A. (1999). Motivational and emotional components affecting male's and female's self-regulated learning. Eur. J. Psychol. Educ. 14, 525-540. doi:10.1007/ BF03172977

Minnaert, A. (2013). Goals are motivational researchers' best friend, but to what extent are achievement goals and achievement goal orientations also the best friend of educational outcomes? Int. J. Educ. Res. 61, 85-89. doi:10.1016/j. ijer.2013.08.002

Minnaert, A., and Vermunt, J. (2010). "Development of self-regulated learning among freshmen: toward consonant or beyond dissonant learning patterns?" in International Handbook on Applying Self-regulated Learning in Different Settings, eds J. de la Fuente and M. Ali Eissa (Almeria, Spain: Education \& Psychology I+D+i), 279-297.

Morgan, P. L., and Fuchs, D. (2007). Is there a bidirectional relationship between children's reading skills and reading motivation? Except. Child. 73, 165-183. doi: $10.1177 / 001440290707300203$

Nevin, A., Thousand, J., Paolucci-Whitcomb, P., and Villa, R. (1990). Collaborative consultation: empowering public school personnel to provide heterogeneous schooling for all -or, who rang that bell? J. Educ. Psychol. Consult. 1, 41-67. doi:10.1207/s1532768xjepc0101_3

Nicholls, J. G. (1984). Achievement motivation: conceptions of ability, subjective experience, task choice, and performance. Psychol. Rev. 91, 328-346. doi:10.1037//0033-295X.91.3.328

Nie, Y., and Lau, S. (2010). Differential relations of constructivist and didactic instruction to students' cognition, motivation, and achievement. Learn. Instr. 20, 411-423. doi:10.1016/j.learninstruc.2009.04.002

Opdenakker, M.-C., Maulana, R., and den Brok, P. (2012). Teacher-student interpersonal relationships and academic motivation within one school year: developmental changes and linkage. Sch. Effect. Sch. Improv. 23, 95-119. doi:10. 1080/09243453.2011.619198

Opdenakker, M.-C., and Van Damme, J. (2007). Do school context, student composition and school leadership affect school practice and outcomes in secondary education? Br. Educ. Res. J. 33, 179-206. doi:10.1080/01411920701208233

Perry, N., Turner, J. C., and Meyer, D. K. (2006). "Classrooms as contexts for motivated learning," in Handbook of Educational Psychology, eds P. A. Alexander and P. H. Winne (Mahwah, NJ: Erlbaum), 327-348.

Pintrich, P. R. (2000a). Multiple goals, multiple pathways: the role of goal orientation in learning and achievement. J. Educ. Psychol. 92, 544-555. doi:10.1037/0022-0663.92.3.544

Pintrich, P. R. (2000b). “The role of goal orientation in self-regulated learning," in Handbook of self-regulation, eds M. Boekaerts, P. R. Pintrich, and M. Zeidner (San Diego, CA: Academic Press), 452-502.

Pintrich, P. R., and De Groot, E. V. (1990). Motivational and self-regulated learning components of classroom academic performance. J. Educ. Psychol. 82, 33-40. doi:10.1037//0022-0663.82.1.33

Prince, A. (2014). Motivation: How to tame the elephant in the classroom? A study aimed at understanding motivation and testing the effect of interventions on the motivation of students in pre-vocational education [Doctoral Dissertation]. Groningen, The Netherlands: University of Groningen, Faculty of Social and Behavioural Sciences, Nieuwenhuis Institute.

Rakoczy, K., Harks, B., Klieme, E., Blum, W., and Hochweber, J. (2013). Written feedback in mathematics: mediated by students' perception, moderated by goal orientation. Learn. Instr. 27, 63-73. doi:10.1016/j.learninstruc. 2013.03.002

Reeve, J., and Jang, H. (2006). What teachers say and do to support students' autonomy during a learning activity. J. Educ. Psychol. 98, 209-218. doi:10.1037/0022-0663.98.1.209

Seegers, G., van Putten, C., and de Brabander, C. J. (2002). Goal orientation, perceived task outcome and task demands in mathematics tasks: effects on students' attitude in actual task settings. Br. J. Educ. Psychol. 72, 365-384. doi:10.1348/000709902320634366

Seppälä, H., and Leskelä-Ranta, A. E. (2006). Does consultation for teachers enhance support for pupils with learning difficulties in transition from school to post-secondary education? J. Appl. Res. Intellect. Disabil. 19, 273-274. doi:10.1111/j.1468-3148.2006.00324_2.x

Shadish, W. R., Cook, T. D., and Campbell, D. T. (2002). Experimental and QuasiExperimental Designs for Generalized Causal Inference. Boston, MA: Houghton Mifflin.

Shapiro, E. S. (1987). Behavioral Assessment in School Psychology. Hillsdale, NJ: Erlbaum.

Shapiro, E. S., and Kratochwill, T. R. (2000). Behavioral Assessment in Schools. Theory, Research, and Clinical Foundations. New York: Guilford Press.

Sheridan, S. M., Clarke, B. L., Knoche, L. L., and Edwards, C. P. (2006). The effects of conjoint behavioral consultation in early childhood settings. Early Educ. Dev. 17, 593-617. doi:10.1207/s15566935eed1704_5

Skaalvik, E. M. (1997). Self-enhancing and self-defeating ego orientation: relations with task and avoidance orientation, achievement, self-perceptions, and anxiety. J. Educ. Psychol. 89, 71-81. doi:10.1037//0022-0663.89.1.71 
Smith, A., and Bell, S. (2015). Towards inclusive learning environments (TILE): developing the 'roadmap for the inclusion of students with special educational needs in vocational education and workplace settings'. Support Learn. 30, 150-160. doi:10.1111/1467-9604.12082

Snijders, T. A. B., and Bosker, R. J. (2012). Multilevel Analysis: An Introduction to Basic and Advanced Multilevel Modeling, 2nd Edn. London: SAGE.

The State of Education in the Netherlands. (2014). Highlights of the 2012/2013 Education Report. Utrecht, The Netherlands: The Dutch Inspectorate of Education.

Torgerson, C. J., and Torgerson, D. J. (2007). The need for pragmatic experimentation in educational research. Econ. Innov. New Technol. 16, 323-330. doi:10.1080/ 10438590600982327

Tunnecliffe, M. R., Leach, D. J., and Tunnecliffe, L. P. (1986). Relative efficacy of using behavioral consultation as an approach to teacher stress management. J. Sch. Psychol. 24, 123-131. doi:10.1016/0022-4405(86)90004-X

van den Berg, R., Vandenberghe, R., and Sleegers, P. (1999). Management of innovations from a cultural-individual perspective. Sch. Effect. Sch. Improv. 10, 321-351. doi:10.1076/sesi.10.3.321.3500

van der Veen, I., and Peetsma, T. (2009). The development in self-regulated learning behavior of first-year students in the lowest level of secondary school in the Netherlands. Learn. Individ. Differ. 19, 34-46. doi:10.1016/j.lindif.2008.03.001

Wang, M. T., and Eccles, J. S. (2013). School context, achievement motivation, and academic engagement: a longitudinal study of school engagement using a multidimensional perspective. Learn. Instr. 28, 12-23. doi:10.1016/j. learninstruc.2013.04.002
Wigfield, A., Byrnes, J. P., and Eccles, J. S. (2006). "Development during early and middle adolescence," in Handbook of Educational Psychology, 2nd Edn, eds P. A. Alexander and P. H. Winne (Mahwah, NJ: Lawrence Erlbaum Associates), 87-113.

Wolters, C. A., Yu, S. L., and Pintrich, P. R. (1996). The relation between goal orientation and students' motivational beliefs and self-regulated learning. Learn. Individ. Differ. 8, 211-238. doi:10.1016/S1041-6080(96)90015-1

Zimmerman, B. J. (1990). Self-regulated learning and academic achievement: an overview. Educ. Psychol. 25, 3-17. doi:10.1207/s15326985ep2501_2

Zimmerman, B. J. (1999). Commentary: toward a cyclically interactive view of self-regulated learning. Int. J. Educ. Res. 31, 545-551.

Zimmerman, B. J. (2000). "Attaining self-regulation: a social cognitive perspective," in Handbook of Self-regulation, eds M. Boekaerts, P. R. Pintrich, and M. Zeidner (San Diego, CA: Academic Press), 13-39.

Conflict of Interest Statement: The authors declare that the research was conducted in the absence of any commercial or financial relationships that could be construed as a potential conflict of interest.

Copyright (C) 2017 Minnaert, Prince and Opdenakker. This is an open-access article distributed under the terms of the Creative Commons Attribution License (CC BY). The use, distribution or reproduction in other forums is permitted, provided the original author(s) or licensor are credited and that the original publication in this journal is cited, in accordance with accepted academic practice. No use, distribution or reproduction is permitted which does not comply with these terms. 


\section{APPENDIX}

TABLE A1 | Detailed description of the self-regulated strategy development (SRSD) training sessions.

Session 1: self-regulation behavior analysis

\begin{tabular}{|c|c|c|}
\hline & Contents & Format \\
\hline Exercise 1: "what is self-regulation?" & $\begin{array}{l}\text { Theory self-regulation } \\
\text { Examples of self-regulating behavior } \\
\text { How to teach self-regulation }\end{array}$ & $\begin{array}{l}\text { Trainer providing information } \\
\text { Group discussion }\end{array}$ \\
\hline Exercise 2: "the SRSD model" & $\begin{array}{l}\text { SRSD six stage model } \\
\text { SRSD key characteristics }\end{array}$ & Trainer providing information \\
\hline $\begin{array}{l}\text { Exercise 3: "talking to students about } \\
\text { used strategies" }\end{array}$ & $\begin{array}{l}\text { Interviewing skills for interaction with student } \\
\text { Identification of needed information for analysis }\end{array}$ & Small group role-playing exercise \\
\hline $\begin{array}{l}\text { Homework: "the case of an individual } \\
\text { student-part } 1 \text { " }\end{array}$ & $\begin{array}{l}\text { Analysis of self-regulating behavior of an individual student using three category form: } \\
\text { desired self-regulation (strategy), current behavior, how to teach }\end{array}$ & Fill in form \\
\hline \multicolumn{3}{|l|}{ Session 2: the student } \\
\hline Exercise 1: "from analysis to procedure" & $\begin{array}{l}\text { Theory self-regulation procedure } \\
\text { Translation of analysis outcomes to procedure using three characteristics: structure, } \\
\text { tailor-made, step-wise. }\end{array}$ & $\begin{array}{l}\text { Trainer providing information } \\
\text { Small group exercise }\end{array}$ \\
\hline $\begin{array}{l}\text { Exercise 2: "teaching a self-regulation } \\
\text { strategy" }\end{array}$ & $\begin{array}{l}\text { Theory teaching a self-regulation strategy } \\
\text { Translation procedure to teaching behavior using four category form: discuss, model, } \\
\text { memorize, practice }\end{array}$ & $\begin{array}{l}\text { Trainer providing information } \\
\text { Small group exercise }\end{array}$ \\
\hline $\begin{array}{l}\text { Homework: "the case of an individual } \\
\text { student-part 2" }\end{array}$ & $\begin{array}{l}\text { Elaboration of individual student case procedure using four category form: discuss, model, } \\
\text { memorize, practice } \\
\text { Contemplate teacher role in the process }\end{array}$ & Fill in form \\
\hline \multicolumn{3}{|l|}{ Session 3: the teacher } \\
\hline Exercise 1: "Three cases of students" & $\begin{array}{l}\text { Three fictional cases of students are discussed } \\
\text { Four steps: analysis, procedure, how to teach, how to implement in classroom } \\
\text { teaching }\end{array}$ & Group exercise \\
\hline \multicolumn{3}{|l|}{ Session 4: coaching } \\
\hline Exercise: "Q\&A" & $\begin{array}{l}\text { Experiences } \\
\text { Strengths and weaknesses of the approach } \\
\text { Questions }\end{array}$ & $\begin{array}{l}\text { Interactive group conversation } \\
\text { Questions and answers }\end{array}$ \\
\hline
\end{tabular}


TABLE A2 | Detailed description of the behavioral consultation (BC) and self-regulated strategy development (SRSD) combined training sessions.

Session 1: student problem analysis

\begin{tabular}{|c|c|c|}
\hline & Contents & Format \\
\hline Exercise 1: "model and vision" & $\begin{array}{l}\text { - BC model: goals, four stages, main characteristics } \\
\text { - Interviewing techniques }\end{array}$ & $\begin{array}{l}\text { - Trainer providing } \\
\text { information } \\
\text { - Video modeling the } \\
\text { consultation interview } \\
\text { - Group discussion }\end{array}$ \\
\hline Exercise 2: "problem identification" & $\begin{array}{l}\text { - First two steps of the model: problem identification and problem analysis } \\
\text { - Identification mismatch consultee and client } \\
\text { - Construction of ideographical theory of client problem }\end{array}$ & $\begin{array}{l}\text { - Small group role-playing } \\
\text { exercise }\end{array}$ \\
\hline $\begin{array}{l}\text { Homework: "the case of an } \\
\text { individual student-part } 1 \text { " }\end{array}$ & $\begin{array}{l}\text { - Analysis of problem of an individual student using seven category form: problem description; } \\
\text { goals not accomplished (both problem identification); task; current task behavior; instruction; } \\
\text { desired strategy (all four problem analysis); mismatch and ideographical theory }\end{array}$ & - Fill in form \\
\hline \multicolumn{3}{|l|}{ Session 2: the student } \\
\hline $\begin{array}{l}\text { Exercise 1: "from analysis to } \\
\text { procedure" }\end{array}$ & $\begin{array}{l}\text { - Theory self-regulation } \\
\text { - SRSD key characteristics } \\
\text { - Translation of analysis outcomes to procedure using three characteristics: structure, tailor-made, } \\
\text { step-wise }\end{array}$ & $\begin{array}{l}\text { - Trainer providing } \\
\text { information } \\
\text { - Small group exercise }\end{array}$ \\
\hline $\begin{array}{l}\text { Exercise 2: "teaching a } \\
\text { self-regulation strategy" }\end{array}$ & $\begin{array}{l}\text { - Theory teaching a self-regulation strategy } \\
\text { - SRSD six stage model } \\
\text { - Translation procedure to teaching behavior using four category form: discuss, model, memorize, } \\
\text { practice }\end{array}$ & $\begin{array}{l}\text { - Trainer providing } \\
\text { information } \\
\text { - Small group exercise }\end{array}$ \\
\hline $\begin{array}{l}\text { Homework: "the Case of an } \\
\text { individual student-part 2" }\end{array}$ & $\begin{array}{l}\text { - Elaboration of individual student case procedure using four category form: discuss, model, } \\
\text { memorize, practice } \\
\text { - Contemplate teacher role in the process }\end{array}$ & - Fill in form \\
\hline \multicolumn{3}{|l|}{ Session 3: the whole class } \\
\hline Exercise 1: "case of a student" & $\begin{array}{l}\text { - The whole process of problem identification, problem analysis, design of procedure, teaching the } \\
\text { strategy }\end{array}$ & $\begin{array}{l}\text { - Video } \\
\text { - Group discussion }\end{array}$ \\
\hline $\begin{array}{l}\text { Exercise 2: "long term and class } \\
\text { wide" }\end{array}$ & - Teaching strategies for the long term and class wide use of the approach & $\begin{array}{l}\text { - Trainer providing } \\
\text { information } \\
\text { - Group discussion }\end{array}$ \\
\hline \multicolumn{3}{|l|}{ Session 4: toward ownership } \\
\hline $\begin{array}{l}\text { Meeting with the school } \\
\text { administrator }\end{array}$ & $\begin{array}{l}\text { - Evaluation of the training: identification of strengths of the approach for the school } \\
\text { - Identification of field situations in which the approach could be used and elaborated toward school } \\
\text { ownership } \\
\text { - Planning for future actions }\end{array}$ & $\begin{array}{l}\text { - Meeting of trainer with } \\
\text { school administrator }\end{array}$ \\
\hline
\end{tabular}


TABLE A3 | The scales used in the study.

Example item

dy.

No. of

items

Source

Original scale

reliability $(\alpha)$

This study

scale

reliability

$(\alpha)$

\begin{tabular}{|c|c|c|c|c|c|}
\hline Task orientation & "I like it when I have learned something new at school" & 5 & Seegers et al. (2002) & 0.77 & 0.83 \\
\hline $\begin{array}{l}\text { Ego-enhancing } \\
\text { orientation }\end{array}$ & "I enjoy getting a better grade in math than my classmates" & 6 & Seegers et al. (2002) & 0.81 & 0.85 \\
\hline $\begin{array}{l}\text { Ego-defeating } \\
\text { orientation }\end{array}$ & $\begin{array}{l}\text { "During classroom tasks, I am afraid that the other children } \\
\text { will notice that I make mistakes" }\end{array}$ & 6 & Seegers et al. (2002) & 0.76 & 0.87 \\
\hline Self-efficacy & "I'm certain I can master the skills taught in class this year" & 6 & Midgley et al. (2000) & 0.78 & 0.83 \\
\hline \multirow[t]{2}{*}{ Self-regulation } & $\begin{array}{l}\text { "Before I begin studying I think about the things I will need } \\
\text { to do to learn" }\end{array}$ & 8 & \multirow{2}{*}{$\begin{array}{l}\text { Pintrich and De Groot } \\
\text { (1990) and Gross and } \\
\text { John (2003) }\end{array}$} & \multirow[t]{2}{*}{0.74} & \multirow[t]{2}{*}{0.78} \\
\hline & "When I feel stressed, I just think about something else" & & & & \\
\hline
\end{tabular}

